\title{
INTEGRATING PERSONNEL MOVEMENT SIMULATION INTO PRELIMINARY SHIP DESIGN
}

\author{
D Andrews, L Casarosa and R Pawling, University College London, UK \\ E Galea, S Deere and P Lawrence, University of Greenwich, UK
}

\section{SUMMARY}

Traditionally, when designing a ship the driving issues are seen to be powering, stability, strength and seakeeping. Issues related to ship operations and evolutions are investigated later in the design process, within the constraint of a fixed layout. This can result in operational inefficiencies and limitations, excessive crew numbers and potentially hazardous situations.

This paper summarises work by University College London and the University of Greenwich prior to the completion of a three year EPSRC funded research project to integrate the simulation of personnel movement into early stage ship design. This integration is intended to facilitate the assessment of onboard operations while the design is still highly amenable to change.

The project brings together the University of Greenwich developed maritimeEXODUS personnel movement simulation software and the SURFCON implementation of the Design Building Block approach to early stage ship design, which originated with the UCL Ship Design Research team and has been implemented within the PARAMARINE ship design system produced by Graphics Research Corporation. Central to the success of this project is the definition of a suitable series of Performance Measures (PM) which can be used to assess the human performance of the design in different operational scenarios.

The paper outlines the progress made on deriving the PM from human dynamics criteria measured in simulations and their incorporation into a Human Performance Metric (HPM) for analysis. It describes the production of a series of SURFCON ship designs, based on the Royal Navy's Type 22 Batch 3 frigate, and their analysis using the PARAMARINE and maritimeEXODUS software. Conclusions on the work to date and for the remainder of the project are presented addressing the integration of personnel movement simulation into the preliminary ship design process.

\section{INTRODUCTION}

\subsection{PERSONNEL MOVEMENT ISSUES IN SHIP DESIGN}

Human Factors (HF) have a significant impact on the design of ships and can be considered at two levels: that of micro-ergonomics and of macro-ergonomics. Microergonomics applies at the detailed level of design, to achieve effective person-machine interfaces and to conduct specific maintenance and repair operations to the ship and its equipment. Historically, macro-ergonomics has been adopted as systems-based term, encompassing HF related organisational and management aspects of the design, including designing the watch-keeping organisation and assessing the trade off between automation and overall manning [1].

Apart from these two levels of HF application there is the important aspect of addressing personnel movement on board ship as a major influence on the operability and usability of the whole ship. This is strongly related to the overall physical arrangements or architecture of the vessel [2]. In order to assess the aspects related to personnel movement in the ship, the configuration at an early stage of the design process has to be accurately yet flexibly modelled. That is to say the model must provide a broad definition of the main configurational features. Up to the present only after the broad form of the ship's layout has been finalised and the traditional naval architectural issues (e.g. powering, stability, strength and seakeeping) have been addressed, are issues related to crewing, ship operations and evolutions then investigated, and only then within those overall design constraints. It can be seen that this relatively late consideration of personnel movement aspects could then result in significant operational inefficiencies and potentially hazardous environments, in particular on a combatant vessel.

Once the ship design is into the detailed development stage then detailed CAD models can be used by specialist experts to assess the relevant Human Factors aspects, as part of evaluating the usability of a given design. A typical example of micro-ergonomics features appraisal is the use of computer generated models in conjunction with virtual reality and simulation software packages to perform real-time 3-D assessment of the practicality of both the operation and maintenance of onboard systems. An example of this was the simulation using, the simulation tool VSTEP, of the operator position and associated sightlines on a dredger [3].

However, it has been argued in Reference 4 that computer aided graphics now provide the ship designer with the ability to consider the ship configuration in a more interactive manner from the earliest stages of design. Thus a wide range of HF issues related to ship 
operations can be considered at these early design stages, as they influence the location, layout and sizing of critical spaces, such as the Bridge, Ship Control Centre, Operations Room, machinery spaces, accommodation areas, and the main access routes linking them. In addition to the main ship design stylistic decisions and considerations of gross layout and operational space design one of the important aspects, where HF considerations can have significant design and cost impact, is in achieving a more efficient configuration, thereby reducing the required manning levels. Recent studies by CETENA S.p.A and the Italian Navy, aimed at reducing costs and optimizing manning, have featured a range of HF and Human-Systems Integration (HSI) issues [5]. Large-scale personnel movement and evacuation has also been investigated for the Royal Navy's Future Aircraft Carrier (CVF) design, given those ships' intended large complement (circa 1200). The second set of authors from the Fire Safety and Engineering Group (FSEG) at the University of Greenwich (UoG) have undertaken simulations of evacuation for that carrier project using their maritimeEXODUS software [6], which is outlined in Section 2.2.

The movement of personnel is one of the key areas of whole-ship usability that can be improved if it is assessed early enough in the design process. Analysis of the specific issue of personnel and passenger flow in evacuation from passenger vessels is currently covered by IMO MSC Circular 1033 [7] which provides a framework for the conduct of evacuation analysis for the whole ship. However, this only takes into account a single aspect of personnel flow (evacuation) and is undertaken to demonstrate compliance with standards, rather than assessment and improvement of the design at an early stage. Furthermore, it may be inappropriate for naval practice and evacuation procedures since it was defined for civilian passenger evacuation.

\subsection{THE JOINT UCL/UoG PROJECT}

Current work in the simulation of personnel movement in ships has focused on evacuation, or specific evolutions covering only part of the design. The UCL Design Research Centre (DRC) and UoG Fire Safety Engineering Group (FSEG) are investigating the application of simulation to the personnel movements through out the ship, in a wider variety of operating conditions. This being undertaken as part of a project entitled "Guidance on the Design of Ships for Enhanced Escape and Operation", which is sponsored by the UK Engineering and Physical Sciences Research Council (EPSRC) and UK Ministry of Defence (MoD) Sea Technology Group (STG) (now the Sea Systems Group in the Defence Procurement Agency) [8]. This three year project, which started in October 2004, has five key objectives:-
1. To explore the impact on naval ship configurational design of issues associated with crew manning numbers, function and movement,

2. To identify key performance measures for successful crew performance in normal and extreme conditions,

3. To extend the ship evacuation software maritimeEXODUS to include additional nonemergency simulation capabilities,

4. To extend the ship design software SURFCON so that it can provide a modelling environment that interactively accepts maritimeEXODUS simulation output for a range of crew evolutions,

5. To demonstrate an approach to ship design that integrates ship configuration design with modelling of a range of crewing issues through PARAMARINE-SURFCON.

This work brings together two software packages and centres of knowledge; PARAMARINE-SURFCON, a graphically-centred early stage ship design tool used by the UCL DRC for preliminary ship design; and maritimeEXODUS, an advanced personnel evacuation and movement simulation tool developed by the FSEG at UoG. The project aims to enable the tools to readily interface and for them to be used to generate guidance, not only on design for evacuation but design for enhanced operational effectiveness with regard to personnel issues.

This multidisciplinary research project is intended to demonstrate the advantages of integrating the cutting edge technologies of Personnel Simulation and Ship Configurational Design. In so doing it will enhance the guidance for all parties in the design, regulation, construction and operation of ships with regard to the main aspects related to personnel movement on board.

\section{RESEARCH TEAMS AND SOFTWARE}

\subsection{THE UCL DESIGN RESEARCH CENTRE AND THE SURFCON DESIGN TOOL}

The UCL Design Research Centre (DRC) is a relatively new research organisation sitting alongside the long standing Naval Architecture and Marine Engineering (NAME) Group within the Department of Mechanical Engineering at University College London. Its main area of research is in computer aided preliminary ship design, using the Design Building Block approach and its implementation in the SURFCON tool $[4,9]$. The UCL DRC also researches into the wider design environment and innovations, such as simulation based design and concurrent engineering, which are altering the way in which ships can be designed. Like the NAME Group, the DRC has an interest in the design of unconventional and innovative vessels, such as the trimaran, and technologies, such as the all electric ship, but with its own particular focus on the ship architecture typified by the Design Building Block approach and its realisation 
through the SURFCON tool. Over the last six years a range of design studies, using the DBB approach and the tool have been undertaken, which are summarised in Reference 9.

SURFCON is part of the PARMARINE software produced by Graphics Research Corporation Limited is an object-based naval architectural design package utilising the commercial ParaSolids modeller as its core [10]. A screenshot of the system in use is shown in Figure 1. The user inserts objects in the "tree pane" on the left of the screen, which shows a logical hierarchal description of the design, whilst any spatial extents or graphical representation are shown in the "graphical pane" on the right of the screen. This provides a constantly updated graphical representation of the current state of the design, a particularly important feature when considering the layout of the vessel. PARAMARINESURFCON is not merely a graphical layout tool, it also contains objects for the assessment of the performance of the design across a range of design capabilities, including resistance and propulsion, stability, manoeuvring and radar cross section, in order that each design study is both hydrostatically balanced and achieves the desired levels of performance. A typical numerical analysis is shown in the top right hand box in Figure 1.

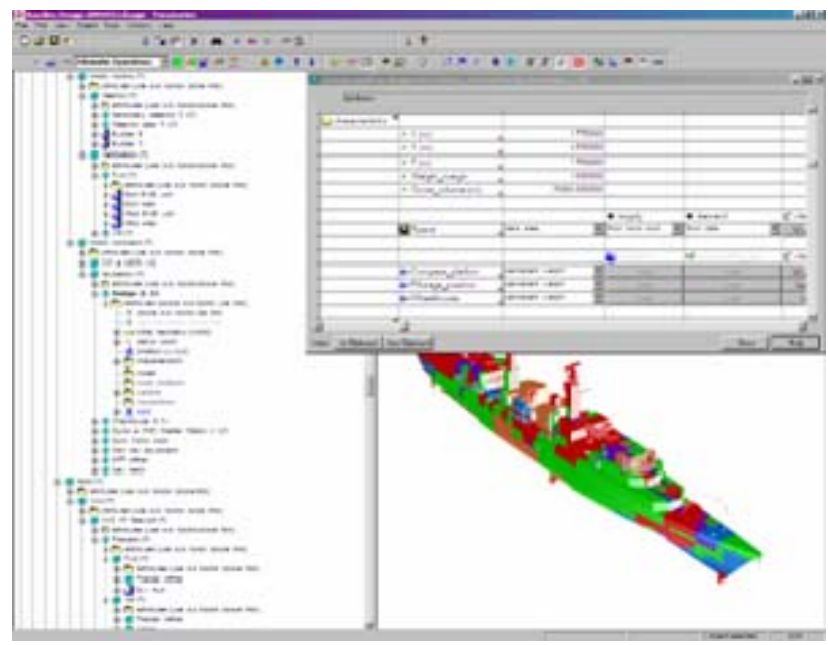

Figure 1: Multiple views of a Design Building Block representation of a frigate using SURFCON.

The fundamental basis of SURFCON and the Design Building Block approach is the Design Building Block object. This is a placeholder or folder in the design space, which contains all descriptive information relevant to a particular function. For example, Figure 2 shows the hierarchical view of a block representing a mess deck for Junior Rates and the corresponding graphical view.

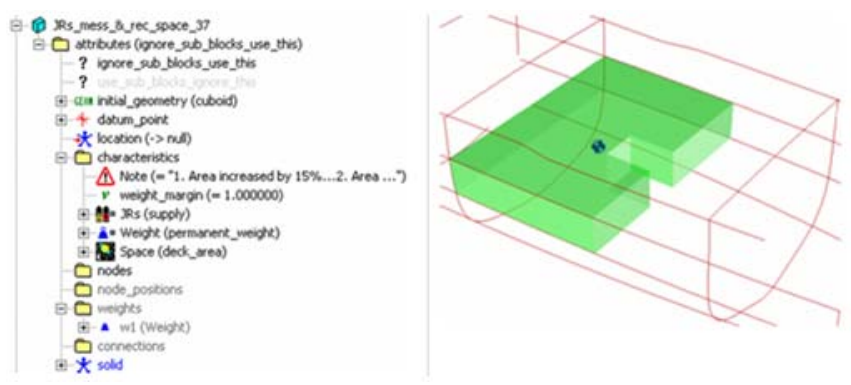

Figure 2: Design Building Block hierarchical and graphical views of a mess deck.

The Design Building Block approach to early stage ship design seeks to encourage a more holistic approach to the development of the ship design solution. Instead of a set of numerical steps or a mechanistic approach, where each aspect of the performance of the design is examined separately and in turn, the integrated nature of the SURFCON implementation in PARMARINE allows aspects of the design's effectiveness to be assessed at the earliest stages of design.

\subsection{UoG FIRE SAFETY ENGINEERING GROUP AND maritimeEXODUS}

The ship evacuation model maritimeEXODUS [6, 11, 12] produced by the Fire Safety Engineering Group (FSEG) of the University of Greenwich was used to perform the personnel simulations presented in this paper. The software has been described in detail in many publications $[6,11,12]$ and so only a brief description of the software is presented here. EXODUS is suite of software to simulate the evacuation and circulation of large numbers of people within a variety of complex enclosures. maritimeEXODUS is the ship relevant version of the software. The software takes into consideration people-people, people-fire and peoplestructure interactions. It comprises five core interacting sub-models: the Passenger, Movement, Behaviour, Toxicity and Hazard sub-models. The software describing these sub-models is rule-based, the progressive motion and behaviour of each individual being determined by a set of heuristics or rules. Many of the rules are stochastic in nature and thus if a simulation is repeated, without any change in its parameters, a slightly different set of results will be generated. It is therefore necessary to run the software a number of times as part of any analysis. These submodels operate on a region of space defined by the GEOMETRY of the enclosure. The Geometry can be specified automatically using a DXF file produced by a CAD package or manually using the interactive tools provided. In addition to the representation of the structure itself, the abandonment system can also be explicitly represented within the model, enabling components of the abandonment system to be modelled individually.

maritimeEXODUS produces a range of output, both graphical and textual. Interactive two-dimensional 
animated graphics are generated as the software is running which allows the user to observe the evacuation as it takes place. In addition, a post-processor virtualreality graphics environment, known as vrEXODUS, is provided enabling an animated three-dimensional representation of the evacuation (see Figure 3).

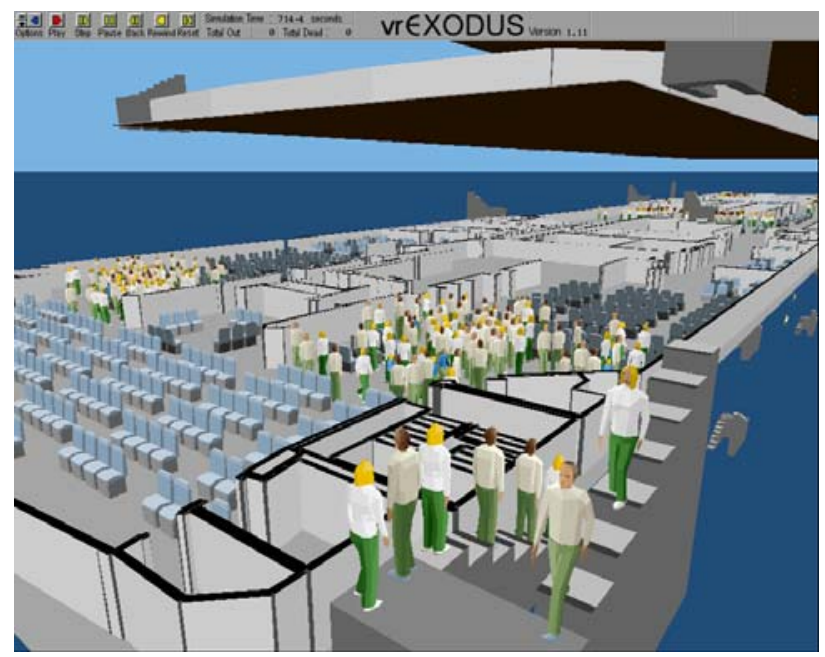

Figure 3: vrEXODUS output showing mustering in a large passenger ship.

The software has a number of unique features such as the ability to incorporate the effects of fire products (e.g. heat, smoke, toxic and irritant gases) on crew and passengers and the ability to include the impact of heel and trim on passenger and crew performance. The software also has the capability to represent the performance of both naval personnel and civilians in the operation of watertight doors, vertical ladders, hatches and 60 degree stairs. Another feature of the software is the ability to assign to passengers and crew a list of tasks to perform. This feature can be used when simulating emergency or normal operations conditions.

As part of the current project, the software's capabilities have been extended through the inclusion of a number of new task capabilities required for normal operations scenarios. Each of these will be briefly described.

'Terminate' command: This feature is used in the normal operations scenarios allowing crew to stay at their last location once a task has been completed. This behaviour allows each individual in the simulation to simply stop once they have completed their assigned tasks. All simulated individuals will remain at their last location when they have completed their assigned tasks and all simulation parameters (e.g. cumulative wait time) associated with the individual cease to measure performance.

'Repeat' command: This feature is used in the normal operations scenarios allowing crew to repeat a predefined set of tasks a number of times. It was designed for the patrol itinerary used in the particular scenario denoted in the Royal Navy as "State 1 Preps" i.e. crew checking that all compartments are correctly secured following an incident. If the itinerary list of tasks assigned to a crew member contains as the last two tasks, 'terminate' followed by 'repeat', the individual will carry out the entire itinerary until the entire ships compliment have completed the simulation.

'Search compartment' command: This feature instructs crew to enter a particular compartment to undertake a search as part of the blanket search scenario.

As the crew member enters the assigned compartment they are assigned a delay time proportional to the floor area of the compartment. The delay time is intended to represent the time required to perform a search of the compartment. Alternatively, the user can specify a minimum and a maximum delay time associated with the search command. If this option is used, the crew member is randomly assigned a search time between the two limits.

'Blanket search' command: This command is specific to the blanket search scenario and instructs specified crew to undertake a detailed search of unoccupied watertight (WT) compartments within a particular WT zone. The user assigns the WT zones to be searched to the appropriate members of the Damage Control and Fire Fighting Party (DCFFP). The software then determines which compartments to search, the order in which they are searched and the location from where the search begins. In the particular blanket search procedure implemented, the search begins from the dispersal station which is the furthest compartment in the assigned WT zone as measured from the Fire Repair Party Post (FRPP) i.e. the starting location of the damage control party. The itinerary assigned to the crew members undertaking the search is made up of multiple 'search compartment' commands. The blanket search operation begins once the relevant crew have all arrived at the dispersal station.

In addition, a separate utility program has been developed, the Human Performance Metric Analyser which automatically constructs the matrix of human performance scores from maritimeEXODUS output that are used in the evaluation of the vessel design.

\section{HUMAN PERFORMANCE METRICS}

In order to gauge the human factors performance of a vessel it is essential to define a range of relevant Evaluation Scenarios (ES) against which the design of the vessel will be tested. These scenarios will effectively define the scope of the challenges that the vessel will be subjected to. In order to gauge vessel performance across a range of criteria, the ES are made up of both evacuation and normal operations scenarios. Relevant evacuation scenarios may include those required by MSC Circular 1033 [4] or their naval equivalent [5]. The normal operations scenarios will very much be dependent 
on the nature and class of vessel and may include for example time to complete 'State 1 Preps'.

As members of the ship's complement may be involved in undertaking different tasks during a particular ES, the ships complement is divided into subgroups. Membership of each subgroup is determined by the nature of the tasks undertaken by the individuals in the particular ES, with each subgroup being made up of personnel undertaking a common set of tasks. These subgroups are labelled Functional Groups (FG). An example of a FG is the 'damage control and fire fighting' group. In practise there may be many FG on board the vessel whose performance must be evaluated e.g. 'Damage control and fire fighting', 'Electronic Warfare', 'Flight', etc.

To evaluate the performance of the FGs in undertaking the tasks required to complete the $\mathrm{ES}$, a range of Performance Measures (PM) are defined. A PM for a naval vessel normal operations scenario may involve the total number of water tight doors (WTD) opened and closed during a particular operation. Some 31 PM have been defined which assess many aspects of crew performance for a surface combatant, such as a frigate. Most PMs are related by a particular theme and so are categorised into groups. Currently, six PM groups have been identified covering the following criteria; Congestion, Environmental, Procedural, Population, Geometric and General. Some of the PMs used in each of these groups are briefly described below.

\section{a) CONGESTION CRITERIA}

This group currently contains two PMs extracted from the IMO Circ. 1033 [7] relating to the level of congestion experienced by FG during an ES. These criteria can be used to identify possible bottlenecks and other causes of congestion. These PM are: $\mathbf{C}_{\mathbf{1}}$ : 'The number of locations in which the population density exceeds $4 \mathrm{p} / \mathrm{m}^{2}$ for more than $10 \%$ of the overall scenario time' and $\mathbf{C}_{2}$ : 'The maximum time that the population density exceeded the regulatory maximum of $4 \mathrm{p} / \mathrm{m}^{2}$ for $10 \%$ of the simulation time'.

\section{b) GENERAL CRITERIA}

This group currently contains five PMs which assess the performance of the FGs in completing general activities associated with the ES. These PMs are; $\mathbf{G}_{\mathbf{1}}$ : average of the time required by each individual to complete all of their assigned tasks; $\mathbf{G}_{\mathbf{2}}$ : average of the time spent in transition; $\mathbf{G}_{3}$ : time to reach final state; $\mathbf{G}_{\mathbf{4}}$ : average time spent in congestion and $\mathbf{G}_{5}$ : average distance travelled.

\section{c) PROCEDURAL CRITERIA}

This group currently contains three PMs which assess the performance of the FGs in completing specific tasks associated with the ES. These PMs include: $\mathbf{P}_{2}$ : 'The average number of operations completed per member of the FG' and $\mathbf{P}_{3}$ : 'The average time per task to complete the FGs assigned tasks'.

\section{d) POPULATION CRITERIA}

This group currently contains two PMs which assess factors associated with the number of crew involved in various activities associated with the ES. These PMs are; $\mathbf{U}_{1}$ : FG population size and $\mathbf{U}_{2}$ : size of the inactive population expressed as a percentage of the number of inactive to the total number of people in the FG.

\section{e) GEOMETRIC CRITERIA}

This group currently contains 14 PMs which assess the performance of the FGs in navigating through various components of the vessel. Individual components of the vessel may be more difficult to traverse than others, for example climbing a ladder is more time consuming than walking the same distance on a deck. Furthermore, all components which require members of the FG to stop and operate them will incur a time penalty which will slow the performance of the FG and lengthen the time required to complete the ES. These PMs include; $\mathbf{M}_{1}$ : the number of WTD used in the ES and $\mathbf{M}_{3}$ : the number of times the FG moved between decks.

The suitability of the vessel layout will be evaluated for fitness of purpose through some combination of the PM resulting from the execution of the ES. The list of evaluation scenarios considered in the current implementation of the HPM are, Evacuation Action Stations, Evacuation Normal Day Cruising, Evacuation Normal Night Cruising, State 1 Preps and Blanket Search.

Collectively the particular combination of ES and PM that results in a meaningful measure of the performance of the crew and vessel are described as a Human Performance Metric (HPM). Clearly, the HPM will be specific to the type and class of vessel being investigated. For example, an aircraft carrier will have a different HPM to a submarine. However, the underlying concept of the HPM will be common to all types of vessels and indeed, some of the various components that make up the HPM may even be similar across different types of vessels.

Thus to evaluate the human performance of a particular vessel design $\mathrm{X}_{1}$, a series of $\mathrm{PMs}$ are evaluating representing the performance of the FGs in a range of ESs as illustrated in Figure 3. The collection and combination of PMs is known as the HPM. Use of the HPM is intended to aid the ship designer in analysing evacuation/normal operations simulations results quickly and efficiently as well as highlighting any problematic areas within each design. The HPM works by systematically evaluating one layout design against another, whether this is two variants of the same design or two completely different ship designs. 


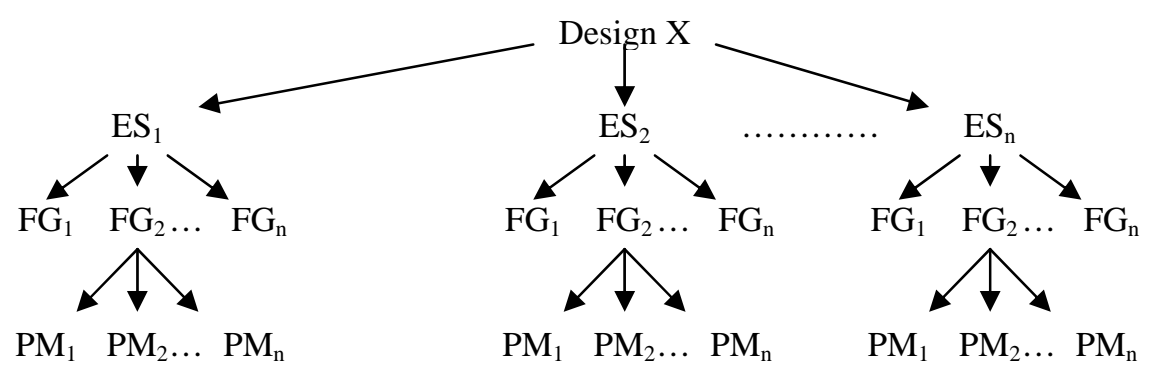

Figure 4: Tree diagram setting out the relationship between the various components of the HPM.

The performance of the vessel in each ES is graded and given a score based on a weighted combination of the PMs. The overall Vessel Performance (VP) is then based on a weighted combination of the scenario scores. The final HPM is depicted in Table 1. The VP for design $\mathrm{X}$ can then be compared against the VP for all other designs to determine which design produced the best overall performance on the basis of the weightings. The matrix is also diagnostic in that it allows the identification of which measures contributed to the poor performance of a failed vessel design, or which PM could be improved in a winning design.

\begin{tabular}{|c|c|c|c|c|c|c|}
\hline Design $X$ & & & & & & \\
\hline \multirow{2}{*}{ Evaluative Scenario } & \multicolumn{5}{|c|}{ Functional Groups } & \multirow[b]{2}{*}{ Scenario Score } \\
\hline & $\mathrm{FG}_{1}$ & $\mathrm{FG}_{2}$ & --- & $\mathrm{FG}_{\mathrm{n}}$ & -- & \\
\hline $\mathrm{ES}_{1}$ & $\mathrm{a}_{1}$ & $\mathrm{a}_{2}$ & -- & $a_{n}$ & -- & $\mathrm{SS}_{1}$ \\
\hline $\mathrm{ES}_{2}$ & $\mathrm{~b}_{1}$ & $\mathrm{~b}_{2}$ & -- & $\mathrm{b}_{\mathrm{n}}$ & -- & $\mathrm{SS}_{2}$ \\
\hline$:$ & $:$ & : & -- & $:$ & -- & --- \\
\hline $\mathrm{ES}_{\mathrm{n}}$ & $\mathrm{d}_{1}$ & $\mathrm{~d}_{2}$ & -- & $\mathrm{d}_{\mathrm{n}}$ & -- & $\mathrm{SS}_{\mathrm{n}}$ \\
\hline : & : & : & -- & : & -- & --- \\
\hline Overall Functional Group Scores & $\mathrm{SFG}_{1}$ & $\mathrm{SFG}_{2}$ & --- & $\mathrm{SFG}_{\mathrm{n}}$ & --- & \\
\hline & & \multicolumn{4}{|c|}{ Overall design performance } & $V P_{D E S I G N(X)}$ \\
\hline
\end{tabular}

Table 1: Summarised form of the HPM for design X.

\section{DEMONSTRATION OF THE} INTEGRATION OF SIMULATION AND DESIGN

\subsection{PROCEDURE}

Figure 5 shows the overall procedure for utilising the two software tools for the analysis of personnel movement in early stage design. The upper boxes show the software tools used and the lower boxes show the operations undertaken in each of the tools. The software set consists of PARAMARINE-SURFCON, maritimeEXODUS and interface software tools developed during the joint EPSRC project.

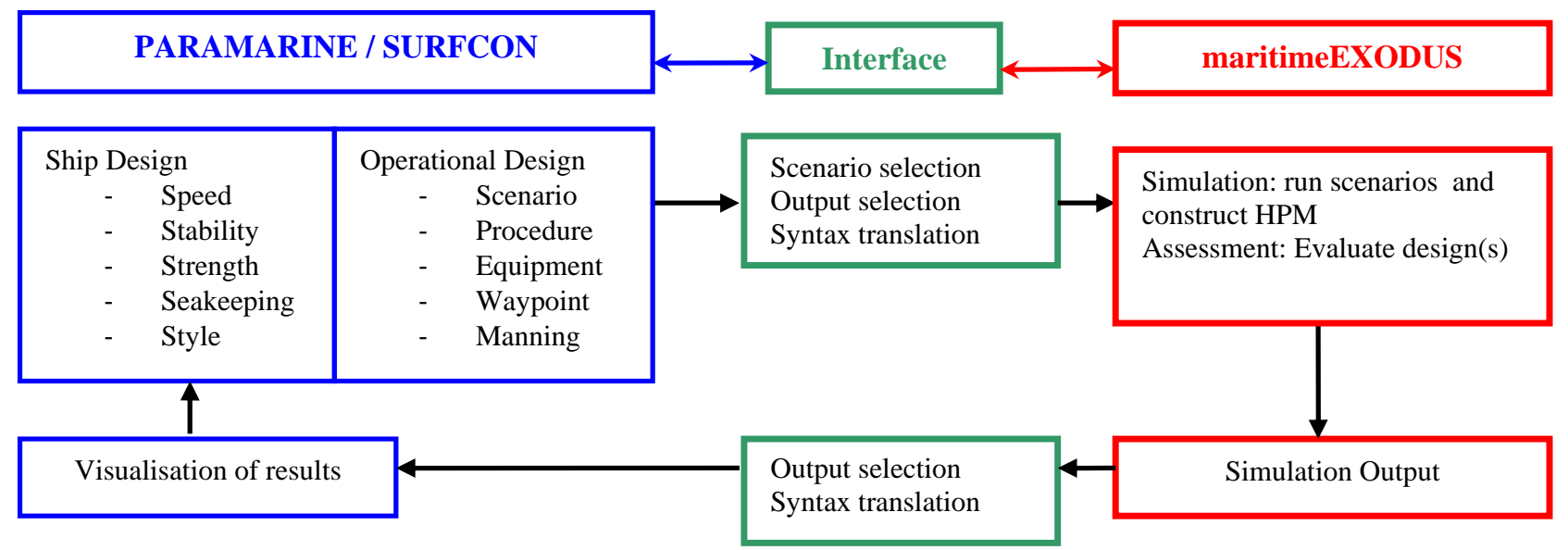

Figure 5: Procedure for personnel movement analysis using separate tools within the joint EPSRC project. 


\section{1 (a) PARAMARINE-SURFCON}

All modelling of the design is undertaken in PARAMARINE-SURFCON, with design features modelled sufficiently to allow the analysis of traditional naval architectural issues. Additional model features are incorporated to allow the investigation of the operations undertaken by the crew. This includes details of the crew's ranks and Functional Groups, and a description of the procedures they are to use in each of the personnel movement scenarios that are to be used to assess the ship design. These features are implemented as a series of tables, formatted to be easily human-readable, and human-comprehensible. These tables are linked to the spatial model of the ship to indicate the main spaces (waypoints) used by each crew member in the scenarios - see Figure 5.

PARAMARINE-SURFCON is also used to visualise the results of maritimeEXODUS simulations in the context of the ship design. In addition to making use of the existing tabular displays of numerical results, the ship design software is used to present graphical representations of both these results and animations of the simulations. The PARAMARINE-SURFCON is being modified by GRC, following specifications developed in the joint EPSRC project, to enhance the graphical display of simulation outputs. This concept of displaying these results, overlaid on the ship design in an interactive manner, places the numerical analyses in context and assists the designer in identifying both the causes of poor performance and possible solutions or improvements for further investigation. It will also contribute to the understanding by designers of the HF related elements of the ship design.

\section{1 (b) INTERFACE TOOLS}

The prototype interface toolset consists of a combination of $\mathrm{C}^{++}$programs, several Excel spreadsheets and macro routines translating and transferring all the information between the two software packages. This is a developmental system, and is not intended to be the final tool, but provides the basic functionality needed to allow SURFCON and maritimeEXODUS to be used together. The implementation of this prototype interface software, and its use, has also allowed a more precise specification of the required functionality to be developed for future tools, thus integrating personnel movement analysis into early stage ship design. This includes issues such as the most efficient way to define the operational procedures to be used by the crew in the simulations and comprehensive and effective postprocessing visualisation and representation of the results.

In transferring information from PARAMARINESURFCON to maritimeEXODUS the interface tools resolve the many parametric links between Design Building Blocks. The complex design model can be reduced to absolute locations of the geometry (the layout as 2D deck plans), connectivity items, (doors and hatches, ladders and stairs), functional spaces (operations room) and important equipment items (such as gas turbines and liferafts). The instructions describing the scenarios to be simulated are defined in the SURFCON model in tabular form, so that they can be linked to the features of the ship design in the spatial model. This information is transferred to maritimeEXODUS via a "scenario generator" tool, which generates the itineraries (instructions) for each crew member in the simulations requested. Although human interaction is required to run the translation tools, no alteration of the representation of the ship is performed here, thus maintaining the consistency of the models used by the design and analysis tools.

\section{1 (c) maritimeEXODUS}

With the layout of the vessel, connections between accessible spaces, simulation scenarios and crew procedures are defined via the Interface tools and maritimeEXODUS is used to perform the simulations. maritimeEXODUS utilises a stochastic model of behaviour, so multiple simulation runs are performed for each of the scenarios. A representative simulation is selected from the multiple runs to populate the HPM. The process of generating the HPM is automatic, a specially developed software tool reading the maritimeEXODUS output and automatically populating the HPM. The Graphical User Interface of maritimeEXODUS can display the design model being assessed and, within the developmental context of the joint EPSRC project, this is used to check for any errors that may have resulted from the translation process. maritimeEXODUS can also display the results of simulations in tabular and graph form.

It can also record animations of the simulation and produce graphical representations of some personnel movement metrics that have a spatial context. Currently these are viewed by the UoG researchers running the maritimeEXODUS simulations and then sent to the UCL naval architects who alter the ship design. Modifications currently being undertaken will allow maritimeEXODUS to fully exploit the developing PARAMARINE-SURFCON functionalities to display results in the form of tables, graphs and graphics overlaid in the same software environment as the ship design. This will close the loop shown in Figure 5 and allow the naval architects to utilise the results of maritimeEXODUS in a more direct manner, as an input in the early stage design of ships. 


\section{2}

\section{VESSELS}

The design being investigated in the joint EPSRC project is that of the Type 22 Batch III Frigate. The Type 22 Batch III is an established front line vessel in the Royal Navy and is being used as the base-line ship design (Variant 1). Importantly for the Joint EPSRC project, a complete definition of the required personnel movements during operation evolutions was available for this well established class of vessel (i.e. the Watch and Station Bill).

The SURFCON model of the vessel is at a very high level of definition relative to most early stage ship designs, based as it is on the General Arrangements of the in-service vessel. In addition to the layout of the internal spaces, the model also includes the connectivity items referred to in Section 4.1, such as doors and ladders. The model also includes items of equipment, such as salvage eductors, life rafts and prime movers, that could require crew interaction in some scenarios. Figure 6 shows an area on No. 2 Deck near amidships, with the connectivity items visible. A two dimensional view, generated from the SURFCON model, is also shown.

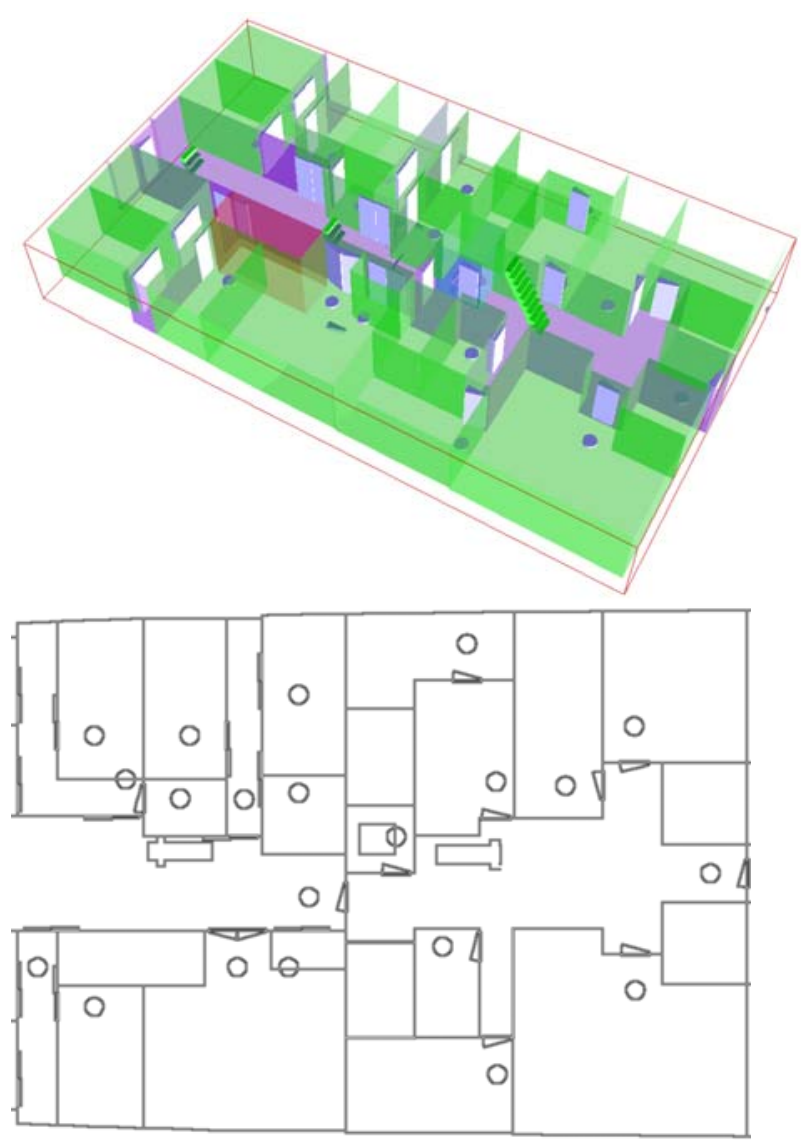

Figure 6: PARAMARINE-SURFCON 3D model with 2D drawing showing level of detail for Type 22 Batch III Frigate.
In addition to the spatial model, the Design Building Blocks also contain numerical properties: -

- $\quad$ Permanent weights that scale with ship size;

- Variable weights for ammunition and stores;

- Consumable fluids, supply and demand;

- $\quad$ Electrical power, supply and demand;

- $\quad$ Propulsive power, supply and demand.

This numerical and graphical model represents a balanced design solution and can be modified by the designer. However, the complexity of the model leads to a very high number of connections between the Design Building Blocks and this increases the time and effort required to modify the model. Table 2 compares the level of detail in the Type 22 Batch III model with previous UCL DRC produced SURFCON designs [14, 15]. Figures 7, 8 and 9 show the SURFCON representations of three designs in Table 2 while Tables 3,4 and 5 summarise each design's principal characteristics.

\begin{tabular}{|l|c|}
\hline \multicolumn{2}{|c|}{ JOINT EPSRC Type 22 Batch III } \\
\hline Design Building Blocks & 453 \\
\hline Equipment Items & 120 \\
\hline Connectivity Items & 348 \\
\hline \multicolumn{2}{|c|}{ UCL LCS Trimaran [14] } \\
\hline Design Building Blocks & 343 \\
\hline Equipment Items & 105 \\
\hline Connectivity Items & 0 \\
\hline \multicolumn{2}{|c|}{ UCL Dock Mothership [15] } \\
\hline Design Building Blocks & 226 \\
\hline Equipment Items & 67 \\
\hline Connectivity Items & 0 \\
\hline
\end{tabular}

Table 2: Comparison of detail in PARAMARINESURFCON design models.

Table 2 shows that, as well as an increase in the number of entities caused by the addition of connectivity items to the model, the overall level of detail in the baseline is much greater than in those models typically produced in early stage ship design. This increases the risk that the personnel movement analysis will not be performed until too late in the design process. This could then mean significant ship design changes revealed by the analysis will be difficult to incorporate. 


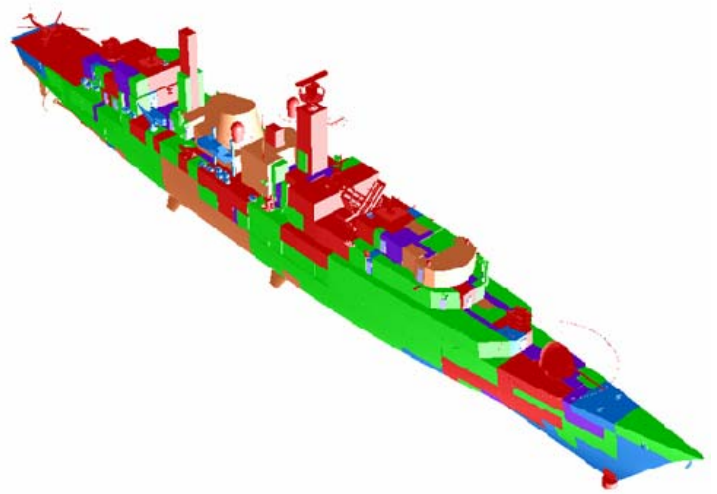

Figure 7: SURFCON Representation of the Type 22 Batch III Frigate.

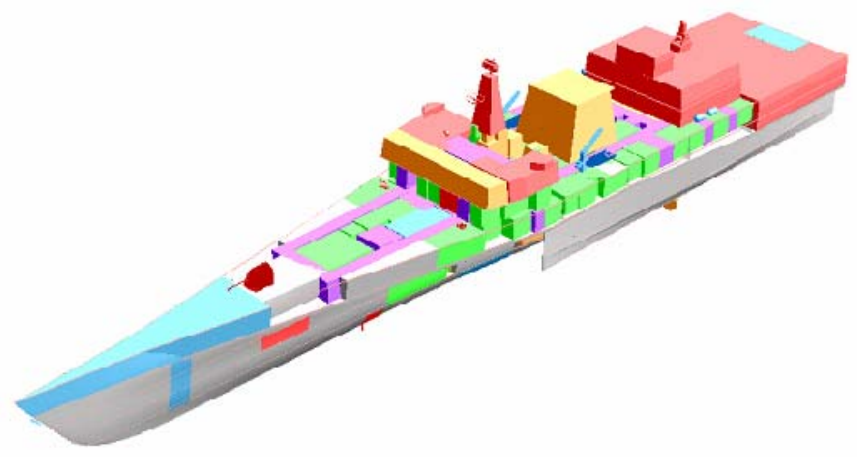

Figure 8: SURFCON Representation of the UCL LCS Trimaran Design Study [14].

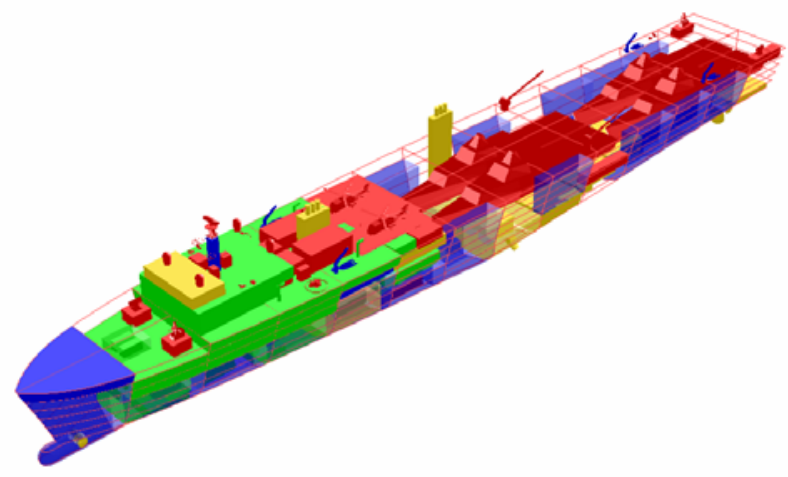

Figure 9: SURFCON Representation of the UCL Dock Variant Mothership Design Study [15].

\begin{tabular}{|l|c|}
\hline Deep Displacement, te & 5320 \\
\hline Waterline Length, m & 136 \\
\hline Overall Length, m & 146.5 \\
\hline Max Upperdeck Beam, m & 14.75 \\
\hline Max Waterline Beam, m & 14.75 \\
\hline Draught, m & 4.75 \\
\hline $\begin{array}{l}\text { Shaft Power, 18 knots, } \\
\text { MW }\end{array}$ & 6 \\
\hline $\begin{array}{l}\text { Shaft Power, 30 knots, } \\
\text { MW }\end{array}$ \\
\hline
\end{tabular}

Table 3: Principal Characteristics of Type 22 Batch III used for PARAMARINE-SURFCON Model.

\begin{tabular}{|l|c|}
\hline Deep Displacement, te & 3212 \\
\hline Waterline Length, m & 136.3 \\
\hline Overall Length, m & 141.3 \\
\hline Max Upperdeck Beam, m & 24.5 \\
\hline Max Waterline Beam, m & 10.5 (main hull) \\
\hline Draught, m & 4.4 \\
\hline $\begin{array}{l}\text { Shaft Power, 20 knots, } \\
\text { MW }\end{array}$ & 8 \\
\hline $\begin{array}{l}\text { Shaft Power, 40 knots, } \\
\text { MW }\end{array}$ & 60 \\
\hline
\end{tabular}

Table 4: Principal Characteristics of UCL LCS Trimaran Design Study used for PARAMARINESURFCON Model [14].

\begin{tabular}{|l|c|}
\hline Deep Displacement, te & 32000 \\
\hline Waterline Length, m & 250 \\
\hline Overall Length, m & 255 \\
\hline Max Upperdeck Beam, m & 38 \\
\hline Max Waterline Beam, m & 31 \\
\hline Draught, m & 7.2 \\
\hline $\begin{array}{l}\text { Shaft Power, 18 knots, } \\
\text { MW }\end{array}$ & 17 \\
\hline $\begin{array}{l}\text { Shaft Power, 25 knots, } \\
\text { MW }\end{array}$ & 47 \\
\hline
\end{tabular}

Table 5: Principal Characteristics of UCL Dock Variant Mothership Design Study used for PARAMARINE-SURFCON Model [15].

A single variant of the Type 22 Batch III design has been produced, which features a double passageway on Numbers 1 and 2 Decks (Variant 2), in contrast to the single passageway of the baseline vessel. These two designs are at the same level of detail, but represent two significantly different solutions to internal access, that in Royal Navy ships have traditionally been adopted, respectively, for frigates (single passageway) and destroyers (double passageway) as stylistic choices, rather than decisions based on analysis. The two sets of main access arrangements for Numbers 1 and 2 Decks are compared in Figures 10 and 11. This variant is a balanced design, with numerical and spatial aspects, 
and so the new design has different overall characteristics - the increased area requirements led to an increase in beam by $2.25 \mathrm{~m}$ to a maximum of $17 \mathrm{~m}$, resulting in a $4.3 \%$ increase in displacement and a small decrease in maximum speed.

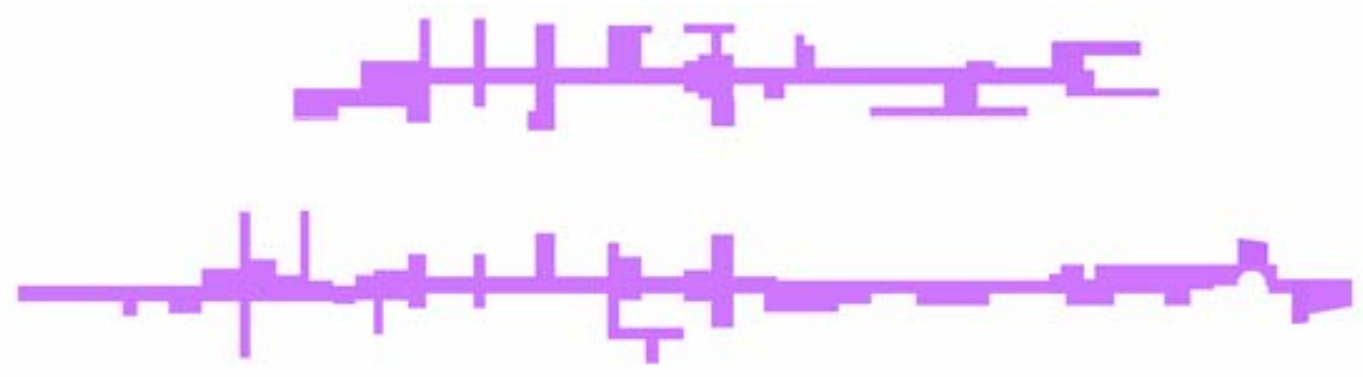

Figure 10: Plan of main passageways on No. 1 \& 2 Decks for Type 22 Frigate Variant 1.

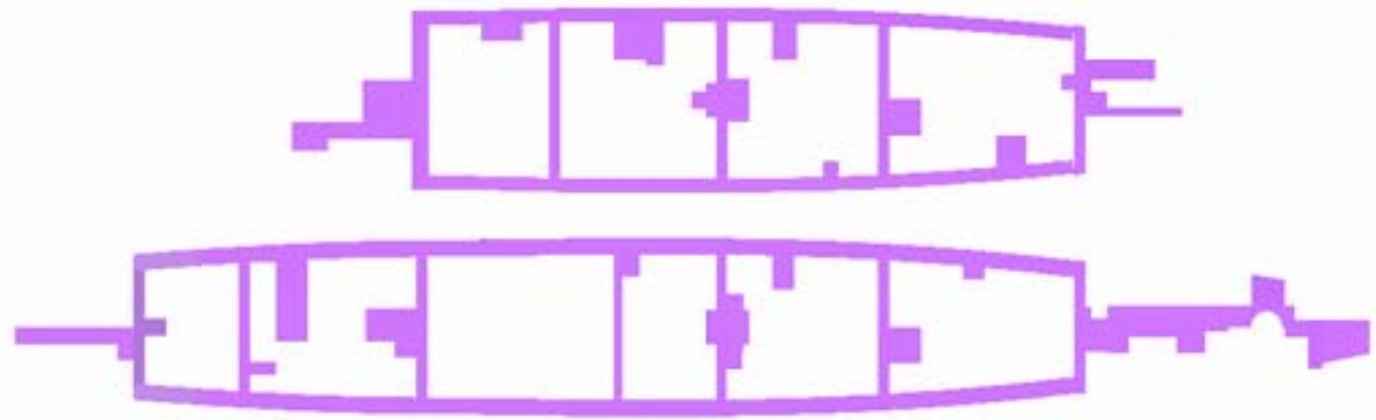

Figure 11: Plan of main passageways on No. 1 \& 2 Decks for Type 22 Frigate Variant 2.

4.3

\section{ANALYSIS OF HPM OUTCOMES}

The use of the HPM concept in evaluating the relative performance of the two design variants is demonstrated in this section. For simplicity, only two evaluation scenarios are considered, one evacuation (Normal Day Cruising: $\mathrm{ES}_{1}$ ) and one normal operations (State 1 Preps: $\mathrm{ES}_{2}$ ) scenario. The aim of this analysis is to determine which design variant is the most efficient in terms of its $\mathrm{HF}$ performance and whether any improvements to that preferred design can be identified.

The evacuation scenario $\left(E S_{1}\right)$ involves the ship's complement moving towards their designated emergency stations ready for the call to abandon ship and so only involves one $\mathrm{FG}, \mathrm{FG}_{1}$. For simplicity, the normal operations scenario $\left(\mathrm{ES}_{2}\right)$ incorporates two FGs, one representing the entire ship's complement $\mathrm{FG}_{1}$ and a second representing the damage control and fire fighting group $\mathrm{FG}_{2}$. Part of the crew in $\mathrm{FG}_{2}$ move to their appropriate FRPP where they check all the fire fighting equipment and dress in full Fearnought clothing. At the same time, other crew members from $\mathrm{FG}_{2}$ close all the water tight (WT) doors on the vessel in order to bring the vessel to WT integrity Condition Z. For simplicity, both design variants have the same ship's complement and number of crew in $\mathrm{FG}_{2}$. This means that the results produced from the HPM will be a direct result of the change in arrangement between the single passageway (Variant 1) design and the double passageway (Variant 2) design.

In total some 18 Performance Metrics (PMs) are used in the analysis and a set of weights has been defined for each of the PMs and ESs. The weights for the PMs associated with pass/fail evacuation criteria take the greatest values, while the weight for the normal operations ES is $50 \%$ greater than the weight for the evacuation scenario.

Providing a greater weight for $\mathrm{ES}_{2}$ emphasises the importance of achieving high HF efficiency in normal operations. In both scenarios, the crew are assumed to take the shortest route to their destination, whether this is an emergency station in the evacuation scenario or a duty station in the normal operations scenario. In reality the crew may take different routes to their target destination however, in order to simplify the analysis, the shortest distance route has been implemented.

As can be seen from the results of the analysis shown in Tables 6 and 7, Variant 1 produces a Vessel Performance (VP) score of 118 while Variant 2 produces a VP score of 132. From this one could conclude that Variant 1 is the more favourable design in terms of its HF performance, according to the measures we have identified, producing an overall vessel performance that is some $12 \%$ better than Variant 2. However, the difference between the two 
design variants is not great and, furthermore, we note that Variant 2 outperformed Variant 1 in the evacuation ES, returning a $5 \%$ better performance, while Variant 1 outperformed Variant 2 in the State 1 Preps ES, returning a $22 \%$ better performance. The greater emphasis placed on the normal operations scenario (through the larger weight given to this scenario) increases the overall difference between the two designs, strengthening the position of Variant 1 over Variant 2.

\begin{tabular}{|c|c|c|c|c|c|c|}
\hline Variant 1 & & & & & & \\
\hline \multirow{3}{*}{ Evaluation scenario } & \multicolumn{4}{|c|}{ Functional Groups } & Scenario Score & Scenario Weight \\
\hline & \multicolumn{2}{|c|}{$\mathrm{FG}_{1}$} & \multicolumn{2}{|c|}{$\mathrm{FG}_{2}$} & & \\
\hline & weight & score & weight & score & & \\
\hline $\mathrm{ES}_{1}$ & 1 & 45.9 & 0 & 0 & 45.9 & 1.0 \\
\hline $\mathrm{ES}_{2}$ & 0.5 & 47.8 & 0.5 & 48.8 & 48.3 & 1.5 \\
\hline \multirow[t]{2}{*}{$\begin{array}{l}\text { Overall functional } \\
\text { group scores }\end{array}$} & \multicolumn{2}{|c|}{81.7} & \multicolumn{2}{|c|}{36.6} & & \\
\hline & \multicolumn{4}{|c|}{ Overall Vessel HF Performance } & & 118 \\
\hline
\end{tabular}

Table 6: HPM for Variant 1 (single passageway vessel).

\begin{tabular}{|c|c|c|c|c|c|c|}
\hline Variant 2 & & & & & & \\
\hline \multirow{3}{*}{ Evaluation scenario } & \multicolumn{4}{|c|}{ Functional Groups } & Scenario Score & Scenario Weight \\
\hline & \multicolumn{2}{|c|}{$\mathrm{FG}_{1}$} & \multicolumn{2}{|c|}{$\mathrm{FG}_{2}$} & & \\
\hline & weight & score & Weight & score & & \\
\hline $\mathrm{ES}_{1}$ & 1 & 43.8 & 0 & 0 & 43.8 & 1.0 \\
\hline $\mathrm{ES}_{2}$ & 0.5 & 62.1 & 0.5 & 55.8 & 59.0 & 1.5 \\
\hline $\begin{array}{c}\text { Overall functional } \\
\text { group scores }\end{array}$ & \multicolumn{2}{|c|}{90.4} & \multicolumn{2}{|c|}{41.9} & & \\
\hline & \multicolumn{4}{|c|}{ Overall Vessel HF Performance } & & 132 \\
\hline
\end{tabular}

Table 7: HPM for Variant 2 (double passageway vessel).

The results from the HPM suggest that Variant 2 is marginally the superior layout for evacuation while Variant 1 returns a significantly better performance in normal operations. This suggests that the overall HF performance of the preferred design (Variant 1) can be enhanced through improving the performance of the vessel in the evacuation scenario.

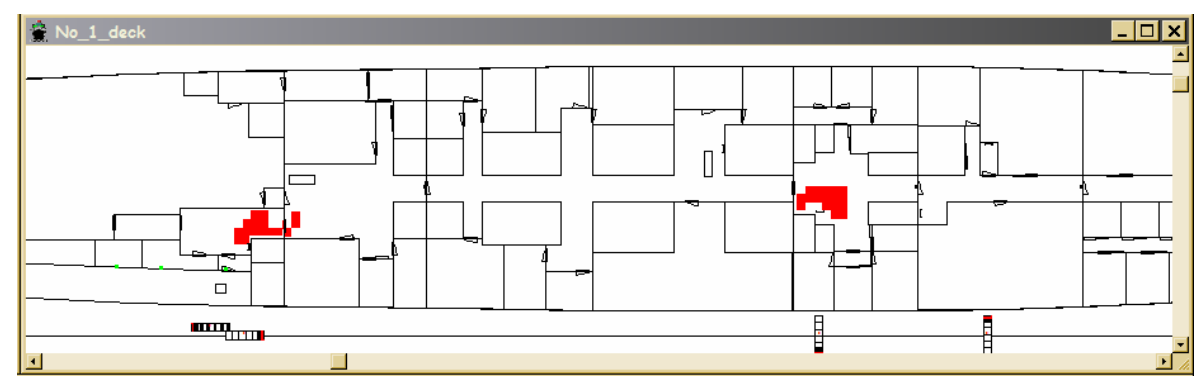

Figure 12: maritimeEXODUS output for Variant 1 showing location of two regions of severe congestion located on No. 1 Deck. 


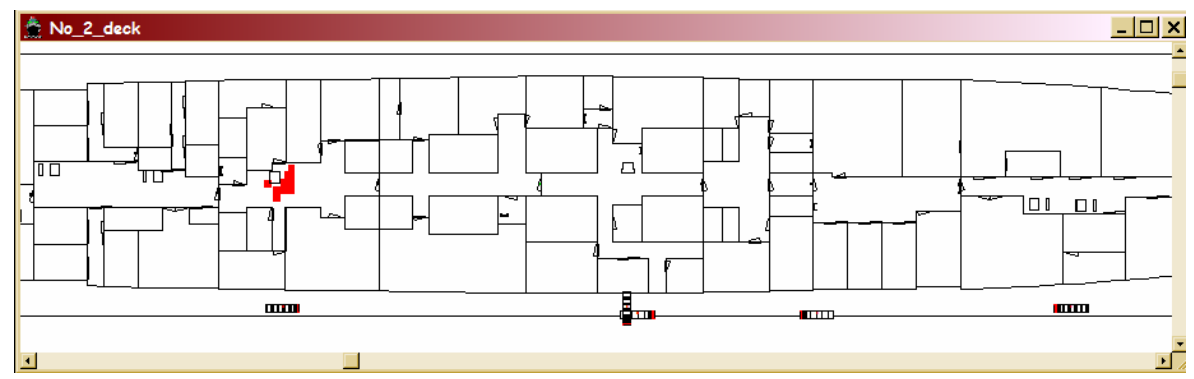

Figure 13: maritimeEXODUS output for Variant 1 showing location of one region of severe congestion located on No. 2 Deck.

A detailed analysis of the Performance Metrics associated with the evacuation ES can suggest areas in which the performance of Variant 1 can be improved. Investigation of the PMs reveals that Variant 1 experienced five areas of severe congestion (three of which are displayed in Figures 12 and 13) compared to only two regions of severe congestion in Variant 2. It is interesting to note that, while both variants comfortably meet the time to muster requirement, they both fail to meet the congestion standards set in [13] for evacuation and so both variants would be deemed to have failed the evacuation requirements.
Clearly the high levels of congestion apparent in ES 1 for Variant 1 reduce the overall performance of the vessel. To address the severe congestion occurring in Variant 1 requires closer investigation of the vessel's layout. Depicted in Figure 14 is the layout of the vessel together with three of the congestion regions. The rear congestion region on No 01 Deck is caused by the large numbers of crew attempting to use the ladder on No 1 Deck leading to 01 Deck. This congestion creates the second area of congestion occurring on the lower No 2 Deck as crew queue to use the ladder leading up to No 1 Deck. The third area of congestion occurs in the forward part of No 1 deck as large numbers of crew queue to use the ladder leading up to 01 Deck.

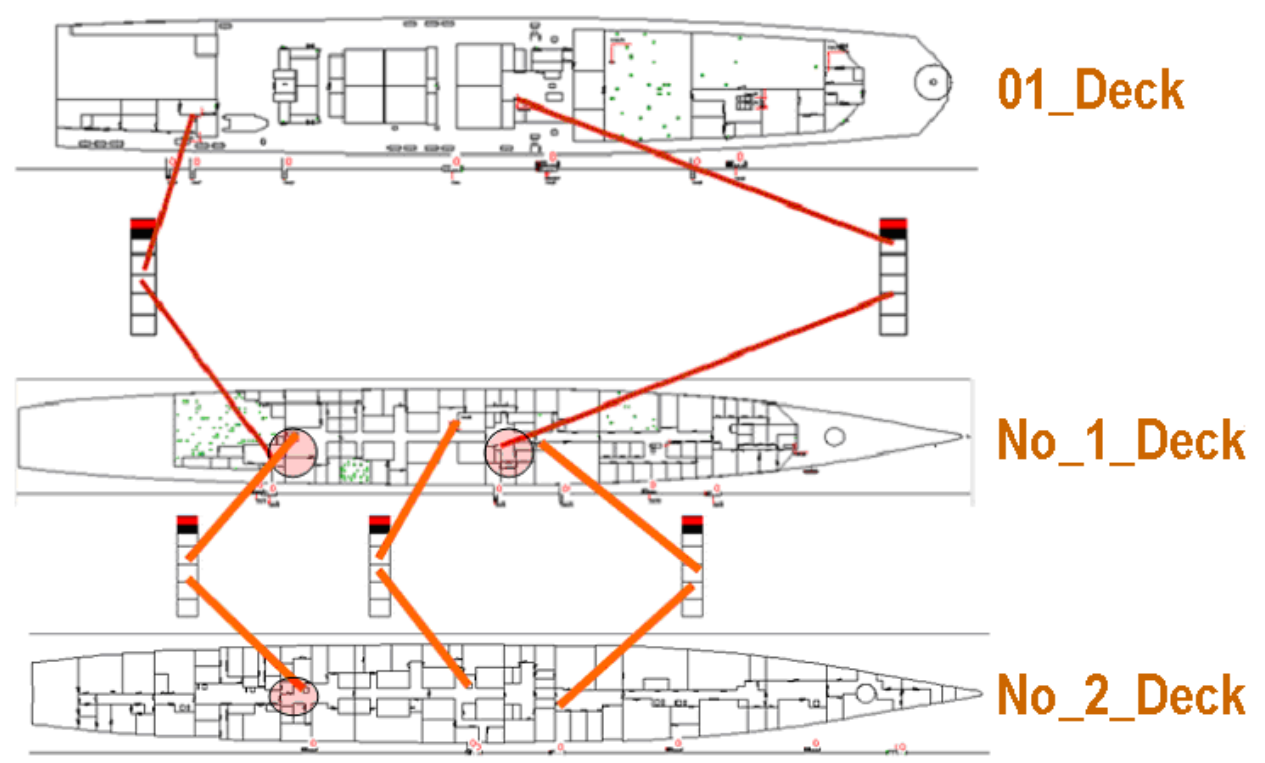

Figure 14: Three decks of Variant 1 indicating location of three large congestion regions (red circles) and associated ladders.

There are a number of possible solutions to these congestion areas. For example, additional ladder capacity up to 01 Deck could be provided at the two congestion regions on No 1 Deck, essentially doubling the capacity of the vertical connections at these two congestion regions. Another possible solution is to provide a third ladder linking No 1 Deck with 01 Deck.
This additional ladder could be located mid way between the existing two ladders. Using this approach crew from both congestion regions on No 1 Deck could be drawn to the new ladder, potentially reducing all three congestion regions (see Figure 15). This later suggestion was adopted as Variant 3 and its performance evaluated. 


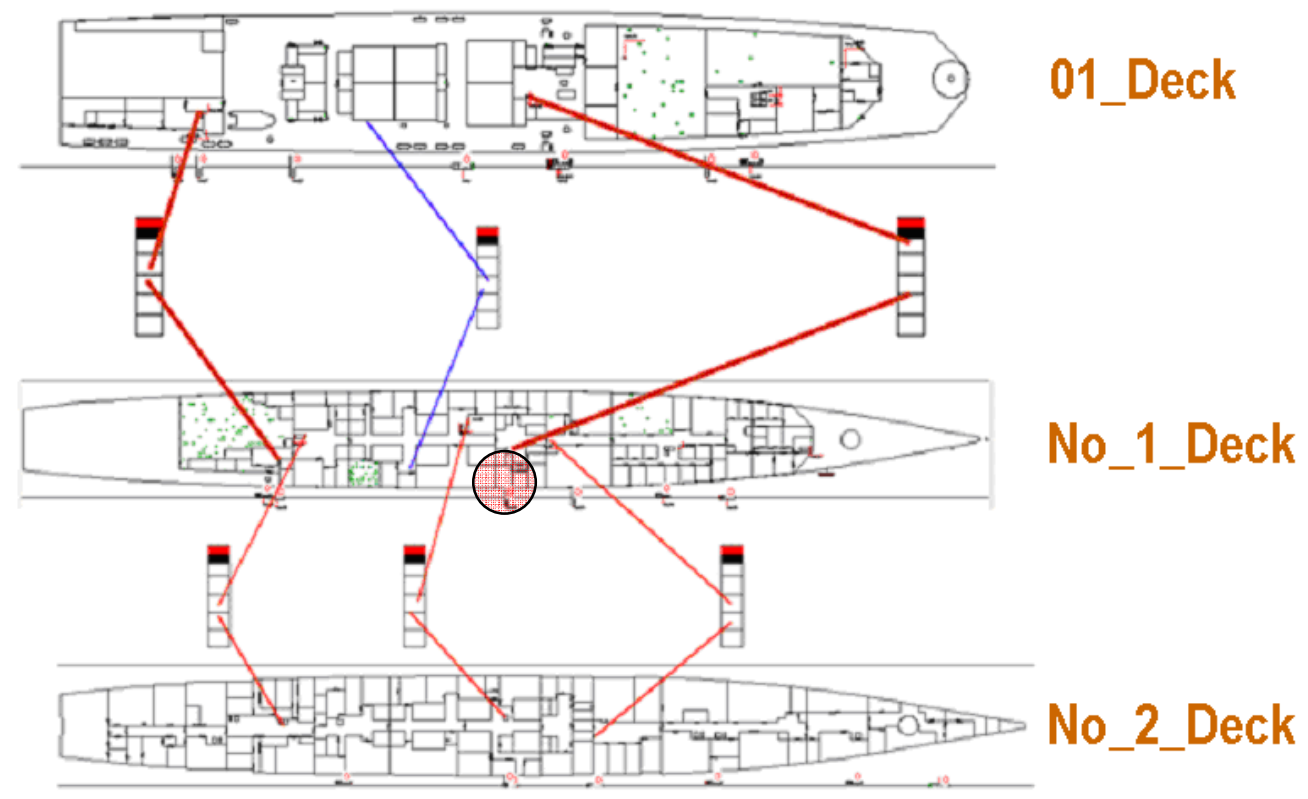

Figure 15: Modified layout of Variant 1 (new Variant 3) with additional ladder connecting No 1 Deck with No 01 Deck.

The proposed modification leads to an overall improvement in vessel performance of some $9.3 \%$ with an improvement in the evacuation scenario of some
$16.8 \%$ and an improvement in the normal operations scenario of some $5 \%$ (see Table 8). We also note that Variant 3 now outperforms Variant 2 across the board.

\begin{tabular}{|c|c|c|c|c|c|c|}
\hline Variant 3 & & & & & & \\
\hline \multirow{3}{*}{ Evaluation scenario } & \multicolumn{4}{|c|}{ Functional Groups } & Scenario Score & Scenario Weight \\
\hline & \multicolumn{2}{|c|}{$\mathrm{FG}_{1}$} & \multicolumn{2}{|c|}{$\mathrm{FG}_{2}$} & & \\
\hline & weight & score & weight & score & & \\
\hline $\mathrm{ES}_{1}$ & 1 & 38.2 & 0 & 0 & 38.2 & 1.0 \\
\hline $\mathrm{ES}_{2}$ & 0.5 & 45.2 & 0.5 & 46.7 & 45.9 & 1.5 \\
\hline \multirow[t]{2}{*}{$\begin{array}{c}\begin{array}{c}\text { Overall functional } \\
\text { group scores }\end{array} \\
\end{array}$} & \multicolumn{2}{|c|}{72.1} & \multicolumn{2}{|c|}{35.0} & & \\
\hline & \multicolumn{4}{|c|}{ Overall Vessel HF Performance } & & 107 \\
\hline
\end{tabular}

Table 8: HPM for Variant 3 (single passageway vessel with additional ladder).

A closer examination of the relevant PMs reveals that Variant 3 experienced three areas of severe congestion, a reduction from the five areas experienced in Variant 1. Two of the three targeted areas of congestion have been completely removed, while the third area (forward area on No 1 Deck, see Figure 15) is greatly reduced. Thus while the overall performance of Variant 3 is greatly improved, it still fails to meet the congestion standards set in [13] for evacuation. It is also worth noting that a number of the PMs associated with Variant 3 have improved through the addition of the single ladder, these include (see Section 3 (b) and Section 3 (e)): G1 (average time required by each individual to complete all of their assigned tasks) 21\% improvement; G4 (average time spent in congestion) 45\% improvement; M2 (number of hatches used in the scenario) $11 \%$ improvement; M5 (number of doors used in scenario) 22\% improvement; and M14 (most times a WT door was operated) $17 \%$ improvement.

A similar detailed analysis to that undertaken for the evacuation scenario could be undertaken for the normal operations scenario which may suggest either procedural or structural changes to Variant 1, improving the performance of the vessel still further. While a detailed analysis is beyond the scope of the current paper, preliminary investigations suggests that, in contrast to the conclusion of the evacuation analysis, the average level of congestion experienced by each crew member is much greater in Variant 2. This detrimentally impacts the performance of the crew. Furthermore, it is important to note that the starting and end locations of crew 
movements and the number of crew in the various starting locations are quite different for these two ESs.

\section{FURTHER WORK}

\subsection{LOWER RESOLUTION MODELS}

To overcome the difficulties found in modifying the high-resolution models of the baseline Type 22 Batch III Frigate and the double-passageway variant, a series of low-resolution models are being developed. These will more closely represent the level of detail usually available in the early stages of ship design. The lowerresolution models will represent four more variants:-

- $\quad$ Baseline Type 22 Batch III;

- Double passageway variant;

- Variant with all cabin accommodation to modern standards (groups of cabins represented by single Building Blocks);

- Medium-resolution cabin based accommodation variant (individual cabins each represented by Building Blocks).

The first two designs will allow a comparison of maritimeEXODUS simulation results from high and low resolution versions of the same design. This is a vital issue if any personnel movement analysis is to be integrated into early stage design. There is a trade off between how much detail is needed in the design, for effective simulation of operations, and the need to retain flexibility for early stage design. A related issue is to investigate how much input is required from the designer to define all aspects of the simulation; certain inputs, such as the Watch and Station Bill, could be generated from a library of options, rather than requiring designer input to commence analyses and thus slowing general design progress.

\section{$5.2 \quad$ HPM}

The ES used to define the HPM will be extended to include several more evacuation and normal operations scenarios. These will include a selection of the evacuation scenarios identified in [13] and the Blanket Search and Family Day normal operations scenarios.

\subsection{SENSITIVITY ANALYSIS}

For a given set of ESs, the conclusions drawn from an analysis of the HPM will be dependent on the user defined weights. An inappropriate setting of the weights may amplify unimportant performance differences between variants and mask important differences. Thus in setting the weights it is essential there is a clear understanding of the priorities in evaluating the designs. To develop a better understanding of the impact the weights may have on an evaluation, a weight sensitivity analysis is currently underway.
As indicated by the project's title, "Guidance on the Design of Ships for Enhanced Escape and Operation”, the main purpose of the project is to provide guidance on this issue. This will cover several areas:

\section{4 (a) THE DESIGN OF SHIPS}

This project aims to provide ship design guidance that can be directly used by the MoD. This will be achieved through the assessment of alternative access and accommodation arrangements. In addition, the project is seeking to identify any features or procedures that could be adopted as "good practice" in design for evacuation and personnel movement related operations.

\section{4 (b) THE LEVEL OF DESIGN DETAIL}

This new capability of simulating, as part of the design, the movement of personnel from the early stages of ship design will affect the manner in which design is undertaken. The development of the design procedure is highly coupled to the development of the software tools and this project aims to provide guidance on the best approaches to be adopted. These will ensure effective assessment of personnel movement issues at an early stage. This includes issues such as the level of detail required in the model and the performance measures, that are most useful, to record effective ways of using them in an interactive design environment. Another issue is how best to iterate the design to a solution. The two approaches currently under consideration are to take a single design and modify it to improve the performance, or to produce a range of designs with different styles and then assess them all in comparison. This would be done against both traditional ship design criteria and the newly-available personnel movement performance criteria. These distinct strategies will be compared and their advantages and disadvantages investigated.

\section{4 (c) THE WIDER DESIGN PROCESS}

Another issue to be addressed is how to integrate, into the overall design process, the assessment of personnel movement in operational scenarios. The procedures used could be fixed and defined by naval operating procedures, or could be treated as another aspect of the design that could be improved as part of the general design development in a given design. In the latter case, the performance of the personnel could become another aspect of the design to be included in cost-benefit and cost-performance analyses. If such aspects are considered then the main outcome for the integration of personnel movement and ship architecture will be to facilitate the exchange of information between the ship designer and experts in manning / personnel operational procedures. This would result in their different needs being incorporated in a single decision making process and facilitate a joint working environment, where the 
ship's material design is evolved alongside the "design of the crew's capabilities".

\section{CONCLUSIONS}

Human Factors influence ship design at many levels. Most HF work relevant to ship design has concentrated on "micro-ergonomics", that is the design of the personmachine interface. Less work has been conducted in the area of whole-ship ergonomics, encompassing issues such as overall configurational layout, personnel movement during operations and operator sightlines and visibility. However, the development of modern computer graphics and of modelling and simulation tools is changing this situation.

This three year project by UCL and UoG is developing tools and approaches for integrating the assessment of personnel movement into the early stages of ship design.

As part of this work, a method, known as the HPM, has been developed to assess the HF performance of naval vessels. This method is intended to be used as a comparative tool, where the performance of one variant is compared with the performance of an alternative variant. However, if appropriate standards are defined, the approach could also be used to evaluate absolute vessel performance. The approach is capable of discriminating between competing designs by selecting the design with the best HF performance, across a range of relevant scenarios. The approach is also diagnostic, providing a means to identify aspects in crew/vessel performance which can be improved. Furthermore, the technique is both systematic and transparent, allowing user priorities to be clearly stated as part of the approach. User priorities can be identified through the selection of the evaluation scenarios to be investigated and the weights assigned to the various components of the HPM.

In addition to the technical issues of modelling and software modification, there is the more general consideration of procedural integration. This project represents the start of bringing whole-ship ergonomics and HF to the fore in ship concept design, such that major design choices can be informed by what has historically been an under-represented issue. This is just one significant area where preliminary ship design can be made more responsive to the aspects of importance not just to owners, but also operators and users.

The two universities and their MoD partner have already explored metrics for the Type 22 frigate and evaluated the issues surrounding the interfacing of the two software packages. The latter task shows that there is a wide range of possible metrics, evolutions and modelling issues appropriate to this interfacing.

While this project addresses the design of naval vessels, the principle behind the proposed approach and the ability of the tools to interface in a seamless manner, has direct applicability, particularly, to the design of commercial passenger vessels.

For ships the overall layout or General Arrangement is the primary mechanism for taking into account the view of the specialist users and of subsystem and equipment designers, while maintaining overall design cohesion. The final output from this project will consist of an integrated tool set, enabling the ship designer to explore the interaction of personnel movement with the ship design, in a range of scenarios. A set of case studies using the tool set will be the primary output, which will provide the basis for guidance to industry and benchmarks for the MoD in the assessment of proposals. This is seen as a means to save considerable time and money in the ship design phases but also in the vessel's through life costs, which can be several times its procurement cost. The project is expected to reinforce the view that, if personnel related considerations are left too late in the design procedure, this could impact significantly on the costs of ownership. It is therefore considered important to introduce consideration of these aspects into the formative stages of the design, in order that trade off studies can comprehend personnel related through life cost implications.

It follows that a more comprehensive design description is required in the preliminary stages, facilitated by the Design Building Block approach. This emphasis on the Human Factors aspects is consistent with the fact that the largest element of the through life cost of a naval combatant is usually directly attributable to the cost of the personnel required to operate the ship and its systems. Design for maintenance is related to efficient personnel movement and the Design Building Block based design description, in conjunction with personnel flow analysis can highlight conflicts early in design. The approach proposed of a Design Building Block based synthesis, in conjunction with the simulation of personnel movement, provides the appropriate front end to a comprehensive design approach for such complex systems. So from investigations, emergent guidance on configurations, which is appropriate to efficient personnel movement, can be provided in a manner that will not conflict with the wider procurement needs. This will lead to clearer requirements, fostering a better basis for competitive responses from industry.

In conclusion, the outcomes from this project are expected to indicate where design can be improved. This should have a direct impact on the through life costs of the vessel, provide a major saving for ship operators, improve the efficiency of the ship design process, reduce design and build time and costs and ensure that the vessel is safer and more efficient for the personnel on board.

\section{ACKNOWLEDGEMENTS}

The authors gratefully acknowledge the support of the UK EPSRC under grants GR/T22100/01 and 
GR/T22117/01, together with the participation of the Sea Technology Group of the Ministry of Defence.

\section{REFERENCES}

1. GILMORE, D J and MILLARD, D, 'Integrating Micro- And Macro-Ergonomics', Proc. of Human Factors and Ergonomics Society Annual Conference, Chicago, October 1997

2. ANDREWS, D J, 'The Use of Simulation in Preliminary Ship Design', Proceedings of $12^{\text {th }}$ International Conference on Computer Applications in Shipbuilding, Busan, Korea, August 2005

3. RINA, 'Sightline Study: Using Real-time 3D Technology to Optimise the Design Process', The Naval Architect, London, April 2003

4. ANDREWS, D J, 'A Creative Approach to Ship Architecture', RINA International Journal of Maritime Engineering, Sept 2003, Discussion and Author's response IJME Sept 2003, Transactions RINA 2004

5. CARTA, A, CATALDI, A, MOLINI, A, RICCO, S and BISSO, C, 'Human-System Integration Issues for a Low-cost, Optimal-manning, High Performances Frigate', INEC 2004 Marine Technology in Transition, Amsterdam, March 2004

6. DEERE, S, GALEA, E R, LAWRENCE, $\mathrm{P}$ and GWYNNE, S, 'The Impact of the passenger response time distribution on ship evacuation performance', The Transactions of The Royal Institution of Naval Architects, Vol 148, Part A1 (Journal of Maritime Engineering), ISSN 1479-8751, 2006

7. International Maritime Organisation, 'Interim Guidelines for Evacuation Analyses for New and Existing Passenger Ships', IMO MSC/Circ 1033, 6 June 2002

8. GALEA, E and ANDREWS, D J, "Guidance on the Design of Ships for Enhanced Escape and Operation”, EPSRC Project Proposal Feb 2004 commenced Oct 2004

9. ANDREWS, D J and PAWLING, R, 'The Application of Computer Aided Graphics to Preliminary Ship Design' Proceedings of IMDC06, Ann Arbor MN May 2006.

10. BOLE, $M$ and FORREST, C, 'Early Stage Integrated Parametric Ship Design', Proccedings of $12^{\text {th }}$ International Conference on Computer Applications in Shipbuilding, Busan, Korea, August 2005

11. GALEA, E R, LAWRENCE, P, GWYNNE, S, SHARP, G, HURST, N, WANG, Z and EWER, J, 'Integrated fire and evacuation in maritime environments', Proceedings of the 2nd International
Maritime Safety Conference on Design for Safety, Sakai Japan, Publisher Ship and Ocean Foundation, 27-30 Oct 2004

12. BOXALL, P, GWYNNE, S, FILIPPIDIS, L, GALEA, $\mathrm{E} \mathrm{R}$ and COONEY, D, 'Advanced Evacuation Simulation Software and its use in Warships', RINA International Conference on Human Factors in Ship Design, Safety and Operation, Feb 2005

13. 'Chapter VII Escape Evacuation and Rescue', "ALLIED NAVAL ENGINEERING PUBLICATION 'ANEP - 77', NAVAL SHIP CODE", NATO Naval Armaments Group, Maritime Capability Group 6, September 2006

14. ANDREWS, D J and PAWLING, R, 'Innovative Ship Design for High Speed Adaptable Littoral Warfare, RINA International Conference Warship 2006: Future Surface Ships, London, June 2006

15. ANDREWS, D $\mathrm{J}$ and PAWLING, $\mathrm{R}$, 'Fast Motherships - A Design Challenge', RINA International Conference Warship 2004: Littoral Warfare \& the Expeditionary Force, London, June 2004 